\title{
Longitudinal associations between non- suicidal self-injury and borderline personality disorder in adolescents: a literature review
}

\author{
Victoria E. Stead ${ }^{1 *}$, Khrista Boylan ${ }^{2,3}$ and Louis A. Schmidt ${ }^{1}$
}

\begin{abstract}
Background: Borderline personality disorder (BPD) in adolescent samples is similar to BPD in adults concerning clinical characteristics. A notable difference is that adolescents with BPD - and adolescents in general - are more likely than adults to present with acute symptoms such as non-suicidal self-injury (NSSI) and suicidal behaviours. BPD is the only disorder in the Diagnostic and Statistical Manual- 5th Edition that includes a criterion of NSSI. Additionally, NSSI is purported to be a developmental precursor of BPD under the biosocial developmental model. Though much cross-sectional data have illustrated the robust association of adolescent NSSI and BPD, no review to date has summarized the longitudinal associations between these phenomena. The aim of this literature review was to summarize what is known about the longitudinal associations between adolescent NSSI and BPD symptoms. Information on the developmental course of NSSI in relation to BPD would be helpful to clinicians, as the rate of NSSI is high in adolescent populations, and research indicates early, possibly BPD-specific interventions are imperative.

Methods: A literature search was conducted using Embase, MEDLINE, and PsycINFO databases and cited reference searches. Criteria included studies of adolescents (age $\leq 18$ at baseline) from either epidemiological or clinical samples, incorporating a longitudinal design, with predictors and outcomes of interest, including both NSSI and BPD diagnosis/symptoms/traits.

Results: Six independent samples were identified that matched our search criteria.

The articles were grouped and reported on separately by population type (epidemiological vs. clinical), and directionality of relations. We identified two epidemiological and four clinical samples. Five samples examined the longitudinal associations of NSSI preceding BPD, three samples measured BPD in adolescence (baseline age $\leq 18$ ), and two of those samples measured BPD at baseline. Both epidemiological studies revealed significant longitudinal associations between NSSI and later BPD/BPD symptoms; however, they differed notably in their methodologies hindering data synthesis across studies. In the clinical studies, findings of the association or predictive relations were not consistent. This is potentially due to differing methodologies, or differences in treatment effectiveness and responsiveness across the samples.

(Continued on next page)
\end{abstract}

\footnotetext{
* Correspondence: steadvi@mcmaster.ca

'Department of Psychology, Neuroscience \& Behaviour, McMaster University,

1280 King St West, Hamilton, ON L8S 4K1, Canada

Full list of author information is available at the end of the article
}

(c) The Author(s). 2019 Open Access This article is distributed under the terms of the Creative Commons Attribution 4.0 International License (http://creativecommons.org/licenses/by/4.0/), which permits unrestricted use, distribution, and reproduction in any medium, provided you give appropriate credit to the original author(s) and the source, provide a link to the Creative Commons license, and indicate if changes were made. The Creative Commons Public Domain Dedication waiver (http://creativecommons.org/publicdomain/zero/1.0/) applies to the data made available in this article, unless otherwise stated. 
(Continued from previous page)

Conclusions: This review highlights the paucity of data that are available examining the longitudinal association between NSSI and BPD within adolescent samples. Thus, it is not possible to reliably comment on how NSSI and BPD are related over time. Future studies will benefit from the measurement of BPD symptoms in very early adolescence, and concurrent measurement of NSSI as well as other forms of suicidal behaviours across adolescence.

Keywords: Borderline personality disorder, Non-suicidal self-injury, Longitudinal, Adolescents

\section{Introduction}

Borderline personality disorder (BPD) is a debilitating mental health disorder characterized by patterns of instability and dysfunction across emotional, behavioural, cognitive, and interpersonal domains. BPD in adolescent samples is similar to BPD in adults concerning prevalence, symptom manifestation and course [1-5]. A notable difference, however, is that adolescents with BPD are more likely than adults to present with "acute" BPD symptomatology, such as suicidal ideation, impulsive behaviours, and recurrent non-suicidal self-injury (NSSI), characterized as the deliberate self-inflicted damage and pain to one's body tissues that is not socially sanctioned and is without suicidal intent $[3,6]$. Furthermore, the NSSI/suicidal behaviours criterion is the most frequently met diagnostic criterion in adolescent BPD samples [3, 7-10]. Of particular interest to this study, BPD is the only disorder in the Diagnostic and Statistical Manual- 5th Edition [DSM-5] that includes a criterion of NSSI [11].

\section{Developmental issues}

Research suggests that BPD symptoms peak in late adolescence around 14 to17 years of age [12]. It is also during this time that self-injury, irrespective of intent, is widely prevalent and has become a major health concern with rates of NSSI ranging from 13 to $28 \%$ in community samples, and as high as 68 to $80 \%$ in inpatient samples [13-15]. We also know from previous cross-sectional studies with adolescents that NSSI and BPD are associated, and this seems to be a robust finding in both clinical [16-20] and community samples [21-23]. More specifically, research has illustrated that BPD symptoms have been shown to be associated with earlier age of onset [10, 23], greater frequency of NSSI [19], and with repeated versus single NSSI episodes [20]. A recent study showed that $95 \%$ of previously hospitalized adolescents with BPD reported engaging in self-injury, with $54 \%$ engaging in at least 50 episodes [18]. Though there is a strong association between NSSI and BPD, and a high frequency of NSSI in clinical settings, it is recognized that NSSI can occur in individuals who do not have BPD [15, 20, 24].

Though research has confirmed the reliability and validity of a BPD construct in adolescents, it is not regularly made in clinical settings. This is often due to various beliefs held by clinicians about the development of BPD [4, 12, 24-27]. One of the deterrents of making a diagnosis of BPD in adolescents, even in clinical settings where the prevalence of BPD is high, is uncertainty about differential diagnosis. This could be inflated due to high rates of NSSI in these settings [24, 27].

NSSI is purported to be a developmental precursor of BPD pathology under the biosocial developmental model [16, 26, 28-30]. Though previous pivotal studies have mainly focused on the cross-sectional associations of NSSI and BPD in adolescent samples [16-23, 30], longitudinal associations between NSSI and suicide attempts to other mental disorders in adolescents [8, 31, 32], adulthood-spanned BPD samples or retrospective adult data $[7,10]$, and longitudinal assessment of suicidal behaviours to BPD [24, 33-36]. Thus, NSSI as a developmental precursor of BPD, which requires longitudinal assessment of at least two time points, remains largely underexamined $[3,7,18,26,37,38]$.

\section{Rationale for the study}

As illustrated above, there is an abundance of research on the development of BPD, yet there is still a gap in the literature assessing the developmental precursors of $\mathrm{BPD}$, particularly as described in the biosocial developmental model $[18,26,28,29,37]$. Cross-sectional research has been valuable in providing us with prevalence rates and associations of NSSI and BPD, but longitudinal studies are necessary to be able to describe the developmental evolution of these phenomena in relation to each other $[18,38]$. Thus, this study aimed to synthesize what is known about the longitudinal associations between NSSI, specifically, and BPD in adolescence, which apparently no review has done. Preliminary data have shown that individuals with BPD most likely engage in both NSSI and suicidal behaviours, and these behaviours together might be more useful for identifying BPD [20]. Though, we specifically wanted to focus on only those studies that included clear measurement of NSSI (no suicidal intent), since NSSI may serve a fundamentally different function than self-injury with suicidal intent $[30,39]$. Additionally, the diagnostic criteria for depression includes suicidal behaviours (i.e., plans, attempts) not NSSI [11], and we wanted to examine a 
precursor exclusively related to BPD and free of transdiagnostic overlap. We also recognize that specific personality and temperament constructs (e.g., emotion dysregulation, impulsivity etc.) should precede the development of NSSI behaviours in adolescents; however, again, these personality constructs are transdiagnostic and not unique to BPD criteria [29].

\section{Clinical implications}

Knowledge about the developmental course of NSSI in relation to BPD would be helpful to clinicians, particularly research which can test i) whether NSSI occurs as a developmental precursor as opposed to correlate of BPD, and ii) whether aspects of NSSI (for example, its frequency, methods or associated factors such as substance use) are correlated or interact to predict BPD diagnosis within a defined time interval. This has clinical relevance, as making a valid diagnosis of BPD in clinic attending adolescents who engage in NSSI is critical, since NSSI is highly prevalent in these settings and research indicates early and disorder-specific interventions are most beneficial $[3,27-29,31,40]$.

\section{Study aims and objectives}

The overall aim of this review was to advance the science of BPD in adolescents by examining whether NSSI may be a developmental precursor of adolescent BPD. The first objective was to identify longitudinal studies reporting on the association (predictive or other) between NSSI and BPD symptoms across adolescence in epidemiological and clinical samples. The second objective was to report on how and when NSSI and BPD were measured to comment on whether measurement procedures include consistent, reliable and valid assessment of developmental course. Third, we aimed to summarize what is known about the longitudinal associations of NSSI and BPD/BPD symptoms to be able to comment on whether the data support NSSI as a precursor of BPD. Finally, we attempted to synthesize these findings to derive suggestions for future research.

\section{Hypothesis}

We know from previous work that although intent of self-injurious behaviours is difficult to assess, it is possible to capture, and there are reliable and valid measures that specifically assess NSSI that can be measured in adolescent samples [6, 30, 39]. Additionally, previous research has established the reliability and validity of BPD in adolescents [3, 27, 41]. Given this information and the numerous studies illustrating the strong association between BPD and NSSI in both epidemiological and clincal studies, and since NSSI is purported to be a precursor of BPD, we hypothesized that we would find longitudinal studies that appropriately measure NSSI and BPD during the developmental period of adolescence that would provide support for NSSI as a precursor of BPD.

\section{Method}

\section{Selection criteria}

Participants, Interventions, Comparisons, Outcomes (PICO) [42]. A Study Design approach was used to generate the research question. Our inclusion criteria were studies of adolescents (sample age $\leq 18$ at baseline) using a longitudinal design. Treatment studies (effect modification) and case studies were excluded. The predictors and outcomes of interest included any measure of NSSI, BPD diagnosis, and BPD symptoms/traits. Only studies that examined NSSI behaviours, and not the proposed NSSI disorder, were included in this review. Studies were eliminated during the screening process if their self-injury variables included any acts with reported suicidal intent, combined behaviours with and without suicidal intent, and unclear suicidal intent (i.e., no confirmation). This was to ensure the examination of NSSI in isolation of suicide attempts. Due to our strict inclusion criteria, the Avon Longitudinal Study of Parents and Children (ALSPAC) cohort, (see Lereya et al., 2013) [43] was not included as the self-injury variable included acts with and without suicidal intent.

\section{Information sources and search}

A search of electronic databases was performed including PsycInfo (1804-June 29, 2018), MEDLINE(R) (1946-June 29, 2018), and Embase (1974-June 29, 2018). Non-English publications were excluded. We specifically wanted to evaluate the literature on adolescent samples. Studies that did not measure either NSSI or BPD at least once prior to age 18 were excluded.

We first searched NSSI and related key terms that included: "injury," "non-suicidal," "non-suicidal self-injury," "NSSI," "non-suicidal self-harm," "self-destructive behaviour," "self-inflicted wounds," "self-injurious behaviour," "self-mutilation," "self-harm." Next, we added key terms for borderline personality disorder by including: "borderline personality disorder," "borderline states," "borderline personality symptoms," "borderline personality features," "BPD," and "borderline"." Lastly, we only wanted to examine adolescent samples, so we included the following key terms into our search: "adolescence," "adolescents," "adolescent development," "adolescent psychopathology," "teens," and "youth."

The screening process was conducted independently by the lead author (V.E.S.) based on the study inclusion criteria outlined above. The titles and abstracts were screened to eliminate non-relevant and duplicate studies. The full texts of the remaining studies were examined 
against inclusion criteria. If there was any uncertainty about the inclusion of a study, the other two authors (K.B. and L.A.S.) were consulted for their opinions.

\section{Results}

Overall, our search produced 562 citations. After removing duplicates, and screening titles and abstracts, 32 complete articles were reviewed, and a total of seven articles met our inclusion criteria (see Fig. 1). Of the seven articles, there were six independent samples (two epidemiological and four clinical). The articles were grouped and reported on separately by population type (epidemiological vs. clinical). To further synthesize findings, we analyzed studies by grouping them on the temporal directionality of the predictor and outcome of interest (e.g., NSSI preceding BPD/BPD symptoms vs. BPD/BPD symptoms preceding NSSI) if NSSI and $\mathrm{BPD}$ were not measured at each time point.

\section{Epidemiological studies} NSSI predicting BPD (see Table 1)

Nakar et al. (2016) examined developmental trajectories of NSSI, suicidal behaviours, and substance misuse in relation to BPD traits later in adolescence. The authors examined adolescents from 26 German schools, using a school randomization sampling model $(N=513 ; 62 \%$ females; mean age at baseline $=14.5$ ) [44]. NSSI was assessed using a modified version of the Deliberate Self-Harm Inventory (DSHI), which measured the prevalence and frequency of NSSI. Participants were asked about lifetime prevalence of NSSI at baseline and past year prevalence in the second and third waves [45]. An ordinal coding scheme was applied to each time point: never engaging in NSSI, occasional NSSI classified as less than five times, and repetitive NSSI classified as five or more occurrences. Participants were then grouped into low, moderate and high-risk groups based on their

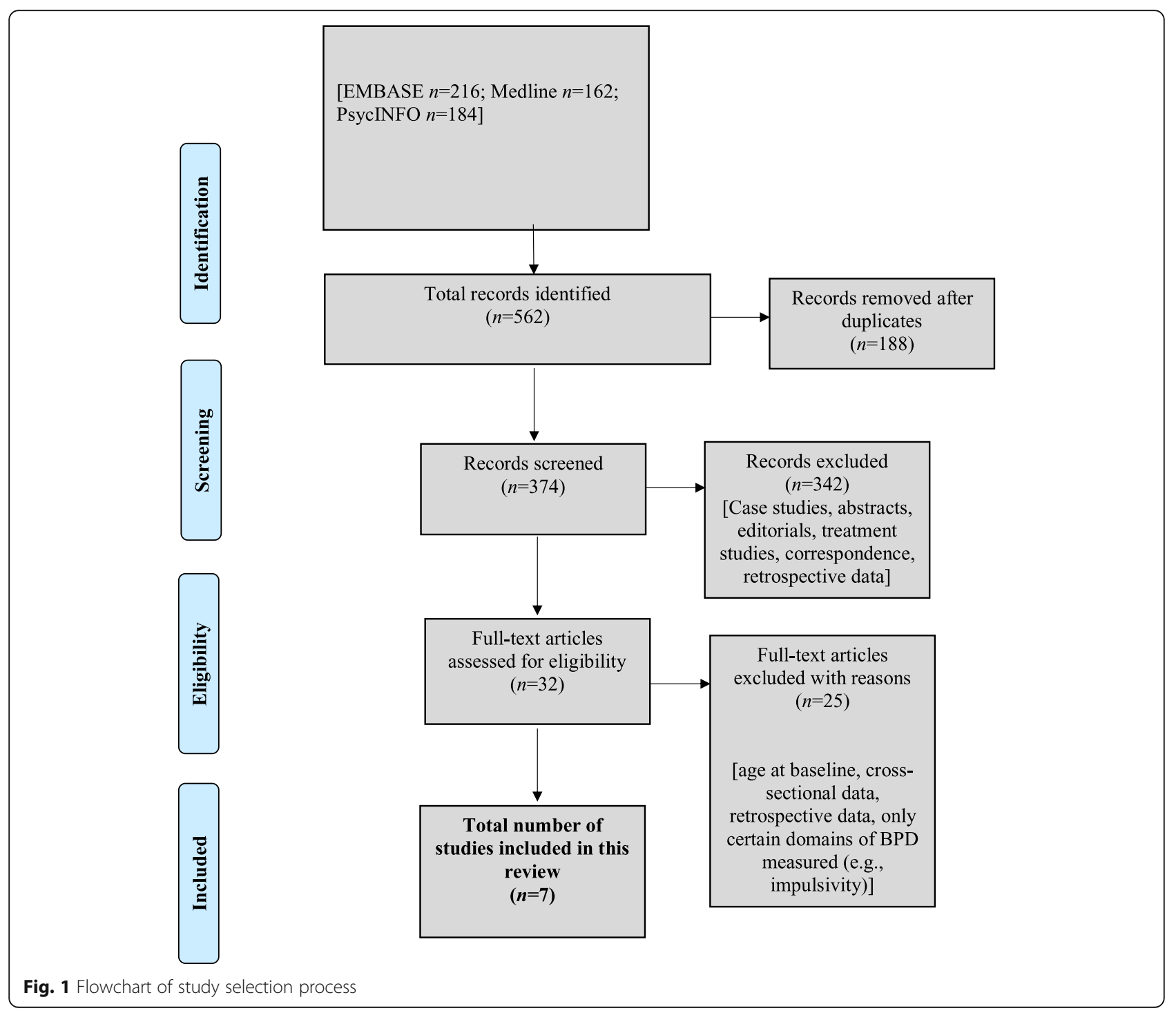




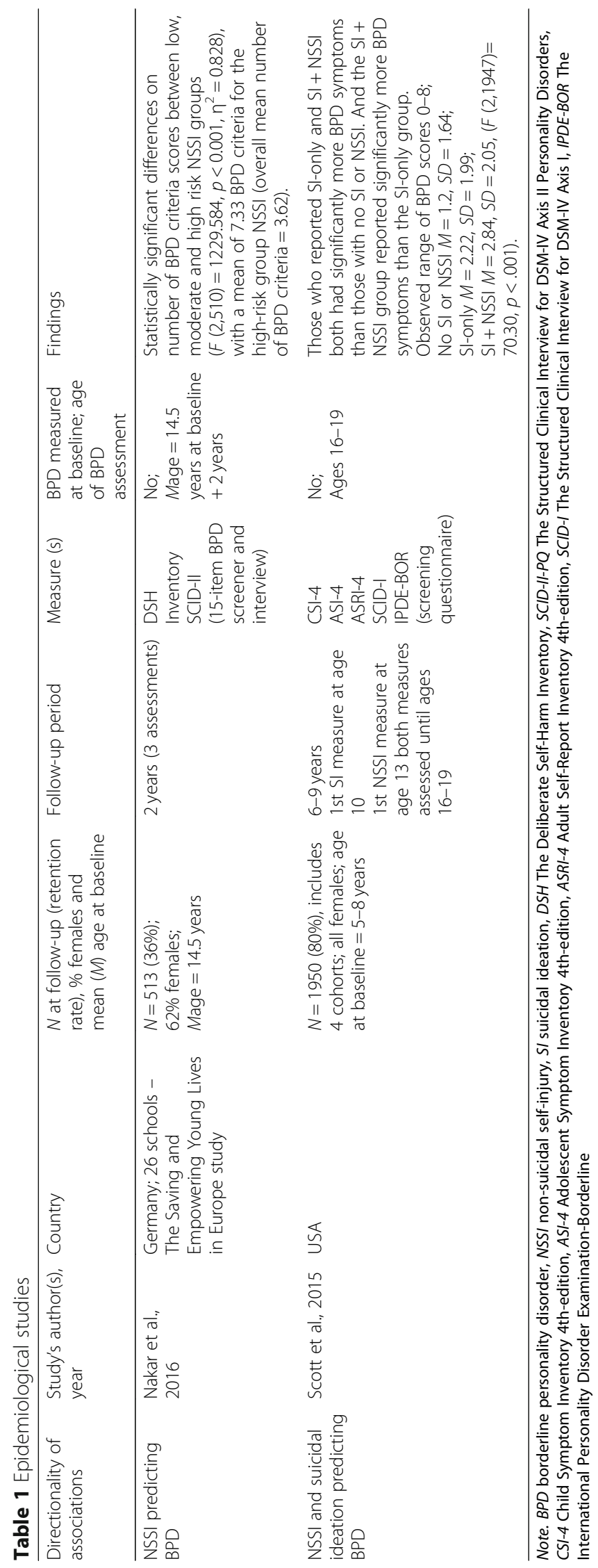


NSSI endorsement profile across all time points. BPD traits were measured using the 15-item BPD screener and the interview from the Structured Clinical Interview for DSM-IV Axis II Personality Disorders (SCID-II-PQ) at the final wave, two years from the baseline assessment $[44,46]$.

Results The high-risk NSSI group $(n=81)$ had a greater number of BPD traits (7.33 symptoms) compared to the low and medium-risk groups. Additionally, the high-risk NSSI group decreased in NSSI behaviours over time. The researchers also examined suicidal behaviours and substance misuse. They reported that there was a high degree of overlap between participants in the high-risk groups for all three phenomena, and this overlap was associated with elevated levels of BPD traits. The same analysis examining the high-risk NSSI group $(n=50)$ in relation to later BPD traits as measured by the SCID-II interview (as opposed to the SCID-II screening questionnaire) was not significant [44].

\section{NSSI and suicidal ideation predicting BPD (Table 1)}

Scott et al. (2015) examined NSSI and suicidal ideation in predicting adolescent BPD in a high-risk urban community sample of adolescent females in Pittsburgh, USA (the Pittsburgh Girls Study, $N=1950$ ) [47]. The focus of their study was to examine histories of suicidal ideation-only and combined suicidal ideation+NSSI during early to late adolescence as prospective predictors of suicide attempts. Participants were between five and eight years old at the intake assessment, and this study included an 11-year, annual follow-up design to age 19.

Suicidal ideation was assessed using the Child Symptom Inventory (age 10), the Adolescent Symptom Inventory (age 12), and the Adult Self-Report Inventory (age 19). Suicidal ideation was considered present at each wave of the study (age 10-19) if a participant endorsed "sometimes" in the past year to suicidal ideation [48-50]. Of the sample, $40 \%$ reported experiencing suicidal ideation at some point between ages ten and 19. NSSI was captured using items from the Structured Clinical Interview for DSM Disorders, Research Version, Non-patient Edition (SCID-I) first at age 13 and again at any point up to and including age 19 [51]. NSSI was coded as being present if it was endorsed at any point between age 13 and 19 . Only $1 \%$ of the sample endorsed NSSI-only, so the authors excluded this group from their primary analyses. Approximately $9 \%$ of the included sample endorsed NSSI. Participants were then grouped based on what behaviours they endorsed as follows: no behaviours (60\%), suicidal ideation-only (31\%), and suicidal ideation+NSSI (9\%) during this age ten to 19 window.
BPD was assessed when participants were ages 16 to 19 , using the The International Personality Disorder Examination-Borderine (IPDE-BOR) screening questionnaire [52]. Importantly, items related to NSSI and suicidal ideation were dropped from the total BPD calculation, an item measuring identity confusion was added, and then all items were summed to create a dimensional score of BPD symptoms.

Results There was an association between the no behaviours, suicidal ideation-only, and combined suicidal ideation+NSSI groups in predicting BPD symptom scores. Results indicated that girls who endorsed both suicidal ideation+NSSI had significantly more BPD symptoms than those with suicidal ideation-only and both groups had significantly more than controls. Thus, the presence of both suicidal ideation and NSSI at any time in adolescence was associated with greater BPD severity at age 16 to 19 [47].

\section{Clinical studies \\ NSSI predicting BPD (see Table 2)}

Four studies examined NSSI in predicting later BPD. These studies included: Groschwitz et al. (2015), Homan et al. (2017), and Koenig et al. $(2017,2018)$ [26, 53-55]. Of note, Koenig et al. $(2017,2018)$ reported on the same sample, and the authors were primarily interested in examining pain sensitivity in adolescents with NSSI and resting-state cardiac function and BPD in adolescents who engage in NSSI, respectively [54,55]. Groschwitz et al. (2015) screened psychiatric clinic attendees' files for terms related to NSSI, and those with at least one episode of NSSI in their medical record were contacted [53]. Participants from the Homan et al. (2017) study were recruited from an inpatient psychiatric unit for self-injury and suicide-related behaviours. The patients' medical records were examined from discharge to five-year follow-up for any diagnosis of BPD or BPD traits [26]. Koenig et al. $(2017,2018)$ recruited participants from a specialized outpatient clinic for risk-taking and NSSI behaviours. These studies varied in the number of participants, ranging from 17 to 116 adolescents at follow-up. Participants were 14 to 16 years of age at baseline. The majority of the samples were females (71$100 \%)$. The follow-up periods of the studies ranged from one to eight years $[26,53-55]$.Note. BPD borderline personality disorder, NSSI non-suicidal self-injury, $S A$ suicide attempts, $S I$ suicidal ideation, $S T$ suicide threats, SITBI-G Self-Injurious Thoughts and Behaviors Interview-German version, SCID-II the Structured Clinical Interview for DSM-IV Axis II Personality Disorders, $S H B Q$ The Self-Harm Behaviour Questionnaire

The semi-structured Self-Injurious Thoughts and Behaviors Interview- German version (SITBI-G) was administered in three of the studies to assess NSSI and 


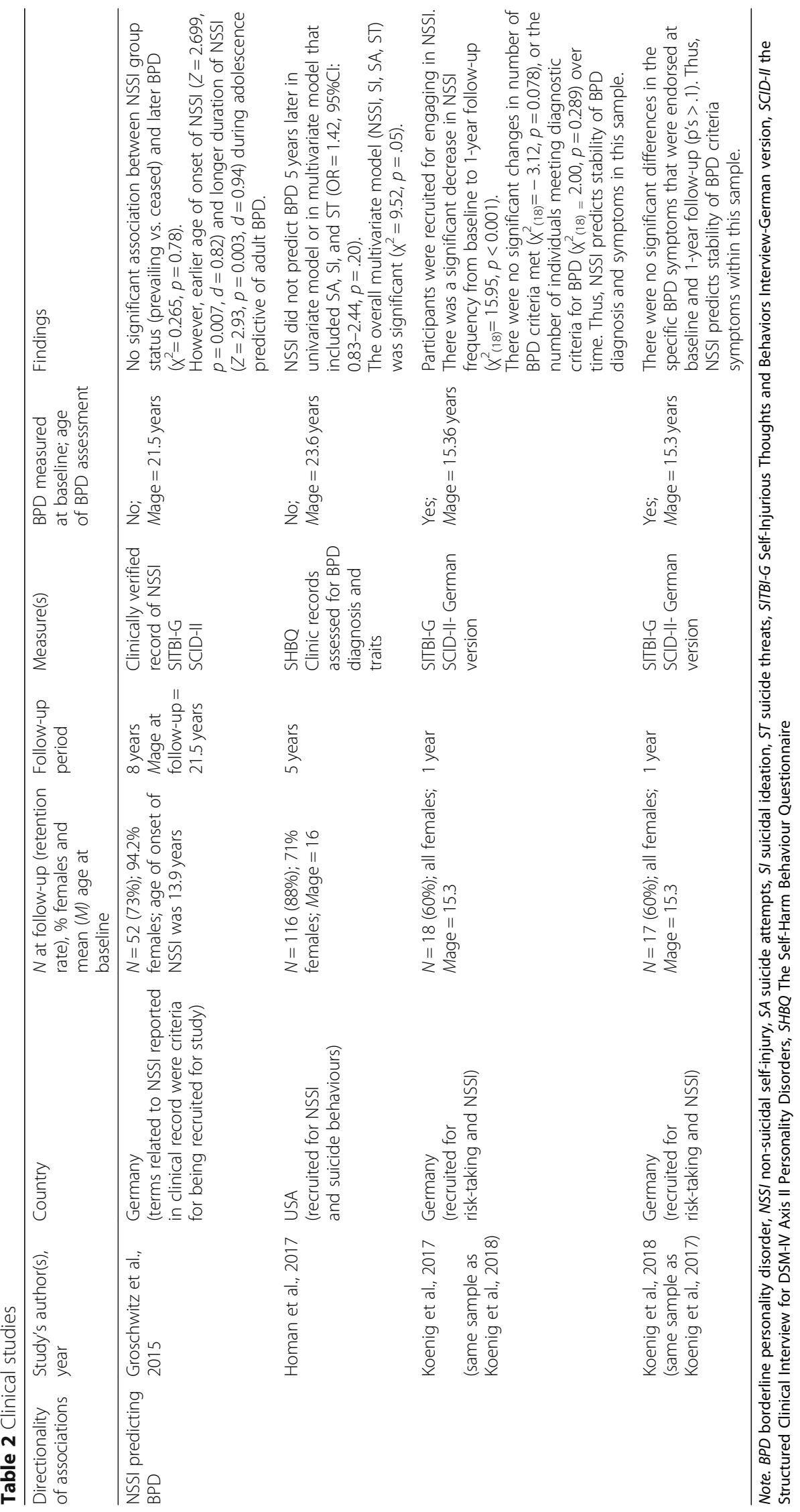


suicide attempts both present and lifetime [53-56]. Participants in the Groschwitz et al. (2015) study were split into two groups, those who reported at least one episode of NSSI within the last year (self-injury prevailing; $n=24$ ), and those who had not engaged in NSSI for at least one year prior to the interview (self-injury ceased; $n=28)$. Koenig et al. $(2017,2018)$ included participants into their study who endorsed at least five incidents of NSSI during the past 12-months (consistent with DSM-5 section 3 diagnostic criteria for NSSI). Lastly, Homan et al. (2017) assessed NSSI via the Self-Harm Behavior Questionnaire (SHBQ), which is a 32-item self-report measure used to assess the frequency and severity of NSSI $[57,58]$. This measure is divided into four sections assessing NSSI, suicide attempts, suicidal ideation and suicide threats [26].

The SCID-II was used to assess for BPD diagnosis in three of the studies [53-55]. However, Homan et al. (2017) assessed BPD through medical record documentation of BPD and BPD traits. BPD was considered a valid diagnosis once participants were 18 years old. Both those patients who were diagnosed with definite and probable BPD were assigned to the BPD group $(n=25)$ [26].

Results Overall, two studies reported no significant associations between NSSI and later BPD. Groschwitz et al. (2015) found no associations between current NSSI group status and BPD diagnoses $\left(\chi^{2}=0.265, p=0.78\right)$. Half of those with BPD reported NSSI within the past year of the eight-year follow-up assessment, and half did not. However, earlier age of onset in adolescence $(Z=2.699, p=0.007, d=0.82)$ and longer duration of engagement of NSSI in adolescence $(Z=2.93, p=$ $0.003, d=0.94)$ were predictive of adult BPD within this sample [53]. Similarly, Homan et al. (2017) did not find an association between adolescent NSSI and later adult BPD as a predictor in the univariate or multivariate analyses $(O R=1.42,95 \% \mathrm{CI}$ : $0.83-2.44, p$ $=.20)$. Conversely, Koenig et al. $(2017,2018)$ found that each BPD criteria symptom assessed independently $(p$ 's $>.1)$, number of BPD symptoms met $\left(\chi^{2}{ }_{(18)}\right.$ $=-3.12, \quad p=0.078)$, and number of individuals meeting diagnostic criteria for BPD $\left(\chi^{2}{ }_{(18)}=2.00, p=\right.$ 0.289 ) to be stable over the year in their sample of adolescents with NSSI behaviours. Though, there was a significant decrease in NSSI from baseline to one-year follow-up $\left(\chi^{2}{ }_{(18)}=15.95, p<0.001\right)$ in these adolscents [26, 53-55].

\section{BPD predicting NSSI (see Table 3)}

Yen et al. (2016) examined adolescent BPD predicting NSSI over a six-month period. Their study aimed to assess prospective predictors of NSSI in adolescents who were admitted to an inpatient psychiatric unit in the United States. Participants were recruited for presenting with increased suicide risk (i.e., recent suicide attempt, NSSI with suicidal ideation, or suicidal ideation), and 78 individuals completed data for the full study (68\% females; mean age at baseline $=15.1$ years) [59].

The Childhood Interview for DSM-IV Borderline Personality Disorder (CI-BPD) was used to assess BPD at baseline and six-month follow-up, and was administered to both parents and adolescents separately. The NSSI/suicide criterion was removed from the total score. The Functional Assessment of Self-Mutilation (FASM) was used to assess methods, frequency and current use of NSSI within the past year [60]. The authors adapted this to be able to capture their six-month follow-up. Behavioural functions of NSSI were also assessed (e.g., automatic reinforcement vs. social reinforcement). Persistence of NSSI was defined as the endorsement of NSSI at both baseline and six-month follow-up using data from all measures (i.e., FASM, CI-BPD, phone check-ins, and clinical reports).

Results In total, $28 \%$ of the sample met criteria for BPD. $54 \%$ of those with BPD had persistent NSSI over the six-month period, and $51 \%$ of the total sample endorsed persistent NSSI. BPD diagnosis status (with NSSI/suicide criterion removed) did not predict persistence of NSSI at the six-month follow-up $\left(\chi^{2}=.19, p<.05\right)$. These results remained when all nine BPD criteria symptoms (including self-injury/suicide) were included in their BPD score [59].

Table 3 Clinical studies

\begin{tabular}{|c|c|c|c|c|c|c|c|}
\hline $\begin{array}{l}\text { Directionality } \\
\text { of associations }\end{array}$ & $\begin{array}{l}\text { Study's author(s), } \\
\text { year }\end{array}$ & Country & $\begin{array}{l}N \text { at follow-up (retention rate), } \\
\% \text { females and mean } \\
(M) \text { age at baseline }\end{array}$ & $\begin{array}{l}\text { Follow-up } \\
\text { period }\end{array}$ & $\begin{array}{l}\text { Measure } \\
\text { (s) }\end{array}$ & $\begin{array}{l}\text { BPD measured } \\
\text { at baseline; age } \\
\text { of BPD assessment }\end{array}$ & Findings \\
\hline $\begin{array}{l}\text { BPD predicting } \\
\text { NSSI }\end{array}$ & Yen et. al, 2016 & $\begin{array}{l}\text { USA } \\
\text { (inpatient- } \\
\text { recruited for } \\
\text { suicide risk) }\end{array}$ & $\begin{array}{l}N=78(77 \%) ; 68 \% \text { females; } \\
\text { Mage }=15.1\end{array}$ & 6-months & $\begin{array}{l}\text { CI-BPD } \\
\text { FASM }\end{array}$ & $\begin{array}{l}\text { Yes; } \\
\text { Mage = } \\
15.1 \text { years }\end{array}$ & $\begin{array}{l}\text { BPD diagnosis (with NSSI/ } \\
\text { suicide criterion removed) } \\
\text { did not predict NSSI at } \\
6 \text {-month follow-up } \\
\left(X^{2}=.19, p<.05\right) \text {. These } \\
\text { results remained with } \\
\text { all } 9 \text { BPD criteria included. }\end{array}$ \\
\hline
\end{tabular}

Note. BPD borderline personality disorder, NSSI non-suicidal self-injury, CI-BPD Childhood Interview for DSM-IV Borderline Personality Disorder, FASM The Functional Assessment of Self-Mutilation 


\section{Discussion}

The first objective of this review was to determine whether studies have measured the longitudinal associations of NSSI and BPD/BPD symptoms in adolescent samples. We identified seven studies (six distinct samples) with longitudinal data with at least one measure of NSSI and BPD in adolescence. The second objective was to report on how and when NSSI and BPD were measured. We hypothesized that at least some of these longitudinal studies would measure BPD and NSSI repeatedly across the developmental period of adolescence, allowing us to test the hypothesis that NSSI may be a precursor of BPD. However, NSSI and BPD were not consistently measured concurrently within studies, limiting confidence in the overall findings.

Five samples examined the longitudinal association of NSSI preceding BPD [26, 44, 47, 53-55], three samples measured BPD in adolescence (baseline age $\leq 18$ ) $[44,54,55,59]$, and two of those samples measured BPD at baseline [54, 55, 59]. Consequently, the most notable gap from this literature is the absence of measurement of adolescent BPD symptoms when NSSI is measured for the first time. Without concurrent baseline measurement of NSSI and BPD in adolescence, it is not clear whether NSSI strongly predicts BPD symptoms, or is simply a correlate $[38,44,47]$. Considering studies have validated the adolescent BPD diagnosis via the CI-BPD with children as young as 11 years old, future work can and should strive to capture early emerging phases of BPD by accurately measuring BPD symptomatology as early as possible in adolescence [12, 27, 61].

Method of BPD measurement differed across studies (e.g., continuous variables vs. dichotomous variables, interviews vs. screeners vs. medical charts), and sometimes yielded different results. It is possible that examining BPD continuously is more representative of the adolescent presentation, as a dynamic spectrum may capture emerging pathology and prodromal individuals who are also impaired and engage in NSSI [35]. Additionally, when BPD screening tools reveal significant results compared to their interview counterparts, we need to be careful with our interpretations, as screening tools for BPD might not be specific enough at detecting true negatives and thus confounding the results [44].

NSSI was measured in different ways, and sometimes split into what seemed like arbitrary groups (e.g., occasional NSSI being less than five occurences vs. repetitive NSSI being five or more occurrences; those who reported at least one episode of NSSI within the last year vs. no NSSI) $[44,53]$. In epidemiological studies, this type of coding might be useful and valid [62], but likely under-represents the range of NSSI frequency and does not capture patterns of NSSI in clinical samples [18]. A recent study has shown that by examining the frequency and time between NSSI acts, specific patterns of NSSI might be more suggestive of BPD in youth (15-25 years) [63]. Additionally, another study found that earlier age of onset and longer duration of NSSI predicted later BPD [53]. Taken together, this emphasizes the importance of precisely measuring frequency, duration, and number of NSSI methods, as it appears specific NSSI patterns may demonstrate clinically essential differences for predicting BPD in adolescents [53, 63].

The studies varied considerably in time to follow-up. Clinical studies are often arduous to conduct and have high attrition rates. However, relatively short follow-up periods (six-months- one year) might not be enough time to elucidate specific behavioural patterns of change associated with adolescent BPD. Additionally, the clinical studies included participants receiving varying types of treatment, and it was unclear, for some of the studies, if and how these different treatments were controlled for in overall analyses $[26,53,59]$. It is possible that the results reflect the effect of treatment on BPD symptoms (and subsequent NSSI behaviours in adolescents with BPD). These points are especially important to consider, since BPD symptomatology is shown to be highly reactive to environmental cues, as rates of BPD symptom fluctuations are seen to be associated with situational factors for these adolescents [4, 28, 29, 64]. In summary, across studies, there were inconsistencies around the timing of measurement (i.e., age and developmental period at which the phenomena were measured), the directionality of the relations, variables not measured in conjunction with each other over time, and how phenomena were operationalized or measured.

Our third objective was to summarize what is known about the longitudinal associations of NSSI and BPD/ $\mathrm{BPD}$ symptoms to be able to comment on whether the data support NSSI as a precursor of BPD. From the epidemiological studies, it would be inaccurate to comment on developmental patterns, due to the vastly differing methodologies across studies, and because BPD was not measured at baseline. Therefore, it is not clear whether BPD preceded or co-occurred with NSSI. From the clinical studies, findings about the association or predictive relation were not consistent. This again may be due to the differing methodologies, or because of differences in treatment effectiveness and responsiveness across the samples. Overall, this review highlights the many gaps in the literature assessing the longitudinal association between NSSI and BPD. Due to the small number of studies and inconsistent study methodologies and findings, it is unclear whether NSSI is a precursor of BPD.

\section{Future directions}

To best characterize the relation between NSSI and $\mathrm{BPD}$ symptoms in adolescents, multi-year prospective 
studies with at least three time points are needed that measure NSSI and BPD symptoms at each wave of the study. Additionally, including and examining both epidemiological and clinical samples is important, as NSSI is highly prevalent in both of these samples, and intergroup differences on developmental precursors are plausible. Precise measurement of methods, frequency, and functions of NSSI, and the other behaviours of the BPD NSSI/suicide criterion (i.e., suicidal behaviours, gestures, and threats), in conjunction with suicidal ideation, should improve prediction. These behaviours are clinically related, and their co-occurrence probably best predicts BPD. In line with the work of Nakar et al. (2016), measurement of substance use, and potentially other more socially acceptable emotion dysregulation behaviours may also provide fundamental information about symptom trajectory profiles of BPD in adolescence, and therefore should be also included [3, 44]. Studying all of these emotion dysregulation behaviours together could provide useful information about early detection of BPD.

The age range of the adolescent sample needs to be considered carefully when comparing studies measuring NSSI and BPD together. There is a peak in symptoms of both NSSI and BPD in adolescence, and these symptoms may be more strongly correlated during this time [12, 13]. Some studies examined NSSI and BPD in youth 13 to 21 or 15 to 25 years of age, and were not included in our review, due to sample age crossing into young adulthood [7, 63]. Developmental stage needs to be considered when examining the developmental course of these phenomena, especially since BPD is conceptualized as a developmental disorder [28]. There are important developmental (e.g., physiological, neurobiological, environmental, etc.) changes that occur during adolescence that warrant BPD and other clinical features to be examined in isolation within this developmental stage, as these changes in biological and environmental systems probably have important implications on behavioural symptom presentations [65-67].

\section{Conclusion}

To optimally investigate the developmental precursors of BPD, researchers should employ prospective research designs that incorporate many aspects of the biosocial model of BPD within a developmental framework [28, 29]. This review highlights the need for concurrent measurement of BPD symptoms and common indicators of emotion dysregulation, such as NSSI, suicidal behaviours and substance use across the developmental window of adolescence. This measurement work is critically important to delineate the developmental precursors associated with a coherent and persistent BPD syndrome in adolescents [63]. This cited research is the foundation for the addition of other tests of the biosocial developmental model of $\mathrm{BPD}$, namely biological (e.g., heart rate variability, temperament/personality etc.), and environmental (e.g., current life situations, treatment, etc.) factors.

\begin{abstract}
Abbreviations
ASI-4: Adolescent Symptom Inventory 4th-edition; ASRI-4: Adult Self-Report Inventory 4th-edition; CI-BPD: Childhood Interview for DSM-IV Borderline Personality Disorder; CSI-4: Child Symptom Inventory 4th-edition; DSH: The Deliberate Self-Harm Inventory; FASM: The Functional Assessment of SelfMutilation; IPDE-BOR: The International Personality Disorder Examination; NSSI: Non-suicidal self-injury; SA: Suicide attempts; SCID-I: The Structured Clinical Interview for DSM-IV Axis I; SCID-II: The Structured Clinical Interview for DSM-IV Axis II Personality Disorders; SHBQ: The Self-Harm Behaviour Questionnaire; SI: Suicidal ideation; SITBI-G: Self-Injurious Thoughts and Behaviors Interview- German version; ST: Suicide threats
\end{abstract}

\section{Acknowledgements \\ The writing of this review was supported in part by a doctoral fellowship from the Social Sciences and Humanities Research Council of Canada awarded to VES under the supervision of KB and LAS.}

Funding

Not applicable.

Availability of data and materials

Not applicable.

\section{Authors' contributions}

VES carried out the literature review search, screened articles and drafted the primary manuscript. KB and LAS provided intellectual direction and guidance, resolved any discrepancies in article inclusion, and provided feedback and improved the manuscript. All authors read and approved the final manuscript.

Ethics approval and consent to participate

Not applicable.

\section{Consent for publication}

Not applicable.

\section{Competing interests}

The authors declare that they have no competing interests.

\section{Publisher's Note}

Springer Nature remains neutral with regard to jurisdictional claims in published maps and institutional affiliations.

\section{Author details}

'Department of Psychology, Neuroscience \& Behaviour, McMaster University, 1280 King St West, Hamilton, ON L8S 4K1, Canada. ${ }^{2}$ Department of Psychiatry and Behavioural Neurosciences, McMaster University, St. Joseph's Healthcare Hamilton, 100 West 5th, Administration - B3, Hamilton L8N 3K7, ON, Canada. ${ }^{3}$ McMaster Children's Hospital, 1200 Main St. West Hamilton, Hamilton, ON L9N 3Z5, Canada.

Received: 3 September 2018 Accepted: 1 February 2019

Published online: 13 February 2019

\section{References}

1. Skodol AE, Gunderson JG, Pfohl B, Widiger TA, Livesley WJ, Siever LJ. The borderline diagnosis I: psychopathology, comorbidity, and personality structure. Biol Psychiatry. 2002;51:936-50. 
2. Bradley R, Zittel Conklin C, Westen D. The borderline personality diagnosis in adolescents: gender differences and subtypes. J Child Psychol Psychiatry. 2005;46:1006-19.

3. Kaess M, Brunner R, Chanen A. Borderline personality disorder in adolescence. Pediatrics. 2014;34:782-93.

4. Sharp C, Wall K. Personality pathology grows up: adolescence as a sensitive period. Curr Opin Psychol. 2018;21:111-6.

5. Zanarini MC, Frankenburg FR, Dubo ED, Sickel AE, Trikha A, Levin A, Reynolds V. Axis I comorbidity of borderline personality disorder. Am J Psychiatr. 1998;155:1733-9.

6. Klonsky ED, Glenn CR. Assessing the functions of non-suicidal self-injury: psychometric properties of the inventory of statements about self-injury (ISAS). J Psychopathol Behav Assess. 2009;31:215-9.

7. Kaplan C, Tarlow N, Stewart JG, Aguirre B, Galen G, Auerbach RP. Borderline personality disorder in youth: the prospective impact of child abuse on non-suicidal self-injury and suicidality. Compr Psychiatry. 2016;71:86-94.

8. Yen S, Gagnon K, Spirito A. Borderline personality disorder in suicidal adolescents. Personal Ment Health. 2013;7:89-101.

9. Zanarini MC, Frankenburg FR, Reich DB, Fitzmaurice G, Weinberg I, Gunderson JG. The 10-year course of physically self-destructive acts reported by borderline patients and axis II comparison subjects. Acta Psychiatr Scand. 2008;117:177-84.

10. Zanarini MC, Frankenburg FR, Ridolfi ME, Jager-Hyman S, Hennen J, Gunderson JG. Reported childhood onset of self-mutilation among borderline patients. J Personal Disord. 2006;20:9-15.

11. American Psychiatric Association. Diagnostic and statistical manual of mental disorders (DSM-5 ${ }^{\circ}$ ). In: American Psychiatric Publishing; 2013.

12. Courtney-Seidler EA, Klein D, Miller AL. Borderline personality disorder in adolescents. Clin Psychol Sci Pract. 2013;20:425-44.

13. Muehlenkamp JJ, Ertelt TW, Miller AL, Claes L. Differentiating non-suicidal self-injury in adolescent outpatients: symptoms of borderline personality disorder. J Child Psychol Psychiatry. 2011;52:148-55.

14. Sadeh N, Londahl-Shaller EA, Piatigorsky A, Fordwood S, Stuart BK, McNiel DE, Klonsky ED, Ozer EM, Yaeger AM. Functions of non-suicidal self-injury in adolescents and young adults with borderline personality isorder symptoms. Psychiatry Res. 2014;216:217-22.

15. Selby EA, Bender TW, Gordon KH, Nock MK, Joiner TE Jr. Non-suicidal selfinjury (NSSI) disorder: a preliminary study. Pers Disord: Theory, Res Treat. 2012;3:167.

16. Crowell SE, Beauchaine TP, Hsiao RC, Vasilev CA, Yaptangco M, Linehan MM, McCauley E. Differentiating adolescent self-injury from adolescent depression: possible implications for borderline personality development. J Abnorm Child Psychol. 2012;40:45-57.

17. Ferrara M, Terrinoni A, Williams R. Non-suicidal self-injury (Nssi) in adolescent inpatients: assessing personality features and attitude toward death. Child Adolesc Psychiatry Ment Health. 2012;6:12.

18. Goodman M, Tomas IA, Temes CM, Fitzmaurice GM, Aguirre BA, Zanarini MC. Suicide attempts and self-injurious behaviours in adolescent and adult patients with borderline personality disorder. Personal Ment Health. 2017;11:157-63.

19. Jacobson CM, Muehlenkamp JJ, Miller AL, Turner JB. Psychiatric impairment among adolescents engaging in different types of deliberate self-harm. J Clin Child Adolesc Psychol. 2008;37:363-75.

20. Muehlenkamp JJ, Ertelt TW, Miller AL, Claes L. Borderline personality symptoms differentiate non-suicidal and suicidal self-injury in ethnically diverse adolescent outpatients. J Child Psychol Psychiatry. 2011:52:148-55.

21. Cerutti R, Manca M, Presaghi F, Gratz KL. Prevalence and clinical correlates of deliberate self-harm among a community sample of Italian adolescents. J Adolesc. 2011;34:337-47.

22. Gratz KL, Latzman RD, Young J, Heiden LJ, Damon J, Hight T, Tull MT. Deliberate self-harm among underserved adolescents: the moderating roles of gender, race, and school-level and association with borderline personality features. Pers Disord: Theory, Res Treat. 2012;3:39.

23. Klonsky ED, Olino TM. Identifying clinically distinct subgroups of self-injurers among young adults: a latent class analysis. J Consult Clin Psychol. 2008;76:22.

24. Greenfield B, Henry M, Lis E, Slatkoff J, Guilé JM, Dougherty G, Zhang X, Raz A, Arnold LE, Daniel L, Mishara BL. Correlates, stability and predictors of borderline personality disorder among previously suicidal youth. European Child Adolesc Psychiatr. 2015;24:397-406.

25. Bondurant $\mathrm{H}$, Greenfield B, Tse SM. Construct validity of the adolescent borderline personality disorder: a review. Canadian Child Adolesc Psychiatr Rev. 2004;13:53.
26. Homan KJ, Sim LA, Fargo JD, Twohig MP. Five-year prospective investigation of self-harm/suicide-related behaviors in the development of borderline personality disorder. Pers Disord: Theory, Res Treat. 2017;8:183.

27. Miller AL, Muehlenkamp JJ, Jacobson CM. Fact or fiction: diagnosing borderline personality disorder in adolescents. Clin Psychol Rev. 2008:28:969-81.

28. Crowell SE, Beauchaine TP, Linehan MM. A biosocial developmental model of borderline personality: elaborating and extending Linehan's theory. Psychol Bull. 2009;135:495.

29. Crowell SE, Kaufman EA, Beauchaine TP. A biosocial model of BPD: theory and empirical evidence. In: Sharp C, Thackett JL, editors. Handbook of borderline personality disorder in children and adolescents. New York: Springer; 2014. p. 143-57.

30. Gratz KL, Dixon-Gordon KL, Tull MT. Self-injurious behaviors in adolescents with borderline personality disorder. In: Sharp C, Thackett JL, editors. Handbook of borderline personality disorder in children and adolescents. New York: Springer; 2014. p. 195-210.

31. Wilkinson P. Non-suicidal self-injury. European Child Adolesc Psychiatr. 2013;22:75-9.

32. Mars B, Heron J, Crane C, Hawton K, Lewis G, Macleod J, Tilling K, Gunnell D. Clinical and social outcomes of adolescent self harm: population based birth cohort study. Br Med J. 2014;349:95954.

33. Brière FN, Rohde P, Seeley JR, Klein D, Lewinsohn PM. Adolescent suicide attempts and adult adjustment. Depress Anxiety. 2015;32:270-6.

34. Consoli A, Cohen D, Bodeau N, Guile JM, Mirkovic B, Knafo A, Mahé V, Laurent C, Renaud J, Labelle R, Breton JJ. Risk and protective factors for suicidality at 6-month follow-up in adolescent inpatients who attempted suicide: an exploratory model. Canadian J Psychiatr Revue Canadienne de psychiatry. 2015;60:S27.

35. Yen $\mathrm{S}$, Weinstock LM, Andover MS, Sheets ES, Selby EA, Spirito A. Prospective predictors of adolescent suicidality: 6-month posthospitalization follow-up. Psychol Med. 2013;43:983-93.

36. Stepp SD, Olino TM, Klein DN, Seeley JR, Lewinsohn PM. Unique influences of adolescent antecedents on adult borderline personality disorder features. Pers Disord: Theory, Res Treat. 2013;4:223.

37. Chanen AM, McCutcheon L. Prevention and early intervention for borderline personality disorder: current status and recent evidence. Br J Psychiatry. 2013:202:s24-9.

38. Ware JH. Linear models for the analysis of longitudinal studies. Am Stat. 1985:39:95-101.

39. Nock MK, Kessler RC. Prevalence of and risk factors for suicide attempts versus suicide gestures: analysis of the National Comorbidity Survey. J Abnormal Pychol. 2006;115:616.

40. Glenn CR, Klonsky ED. Nonsuicidal self-injury disorder: an empirical investigation in adolescent psychiatric patients. J Clin Child Adolesc Psychol. 2013:42:496-507.

41. Sharp C, Ha C, Michonski J, Venta A, Carbone C. Borderline personality disorder in adolescents: evidence in support of the childhood interview for DSM-IV borderline personality disorder in a sample of adolescent inpatients. Compr Psychiatry. 2012;53:765-74.

42. Liberati A, Altman DG, Tetzlaff J, Mulrow C, Gøtzsche PC, loannidis JP, Clarke M, Devereaux PJ, Kleijnen J, Moher D. The PRISMA statement for reporting systematic reviews and meta-analyses of studies that evaluate health care interventions: explanation and elaboration. PLoS Med. 2009:6:e1000100.

43. Lereya ST, Winsper C, Heron J, Lewis G, Gunnell D, Fisher HL, Wolke D. Being bullied during childhood and the prospective pathways to self-harm in late adolescence. J Am Acad Child Adolesc Psychiatry. 2013;52:608-18.

44. Nakar O, Brunner R, Schilling O, Chanen A, Fischer G, Parzer P, Carli V, Wasserman D, Sarchiapone M, Wasserman C, Hoven CW. Developmental trajectories of self-injurious behavior, suicidal behavior and substance misuse and their association with adolescent borderline personality pathology. J Affect Disord. 2016;197:231-8.

45. Brunner R, Kaess M, Parzer P, Fischer G, Carli V, Hoven CW, Wasserman C, Sarchiapone M, Resch F, Apter A, Balazs J. Life-time prevalence and psychosocial correlates of adolescent direct self-injurious behavior: a comparative study of findings in 11 European countries. J Child Psychol Psychiatry. 2014;55:337-48.

46. Gibbon M, Spitzer RL, Williams JB, Benjamin LS, First MB. Structured clinical interview for DSM-IV axis II personality disorders (SCID-II): American Psychiatric Publishing; 1997. 
47. Scott LN, Pilkonis PA, Hipwell AE, Keenan K, Stepp SD. Non-suicidal selfinjury and suicidal ideation as predictors of suicide attempts in adolescent girls: a multi-wave prospective study. Compr Psychiatry. 2015;58:1-0.

48. Gadow K, Sprafkin J. Child symptom inventories Manual-4. Stonybrook. In: New York: checkmate plus; 1994

49. Gadow KD, Sprafkin J. Adolescent symptoms Inventory-4: screening manual. Stony brook. In: New York: checkmate plus; 1997.

50. Gadow K, Sprafkin J, Weiss M. Adult self-report inventory 4 manual. Stony brook. In: New York: checkmate plus; 2004.

51. First MB, Gibbon M, Spitzer RL, Williams JBW. Structured clinical interview for DSM-IV Axis I disorders (SCID-I). Washington, DC: American Psychiatric Press; 1997.

52. Loranger AW, Sartorius N, Andreoli A, Berger P, Buchheim P, Channabasavanna SM, Coid B, Dahl A, Diekstra RF, Ferguson B, Jacobsberg LB. The international personality disorder examination: the World Health Organization/alcohol, drug abuse, and mental health administration international pilot study of personality disorders. Arch Gen Psychiatry. 1994;51:215-24

53. Groschwitz RC, Plener PL, Kaess M, Schumacher T, Stoehr R, Boege I. The situation of former adolescent self-injurers as young adults: a follow-up study. BMC Psychiatr. 2015;15:160.

54. Koenig J, Rinnewitz L, Niederbäumer M, Strozyk T, Parzer P, Resch F, Kaess M. Longitudinal development of pain sensitivity in adolescent non-suicidal self-injury. Psychiatric Res. 2017;89:81-4.

55. Koenig J, Weise S, Rinnewitz L, Parzer P, Resch F, Kaess M. Longitudinal covariance of resting-state cardiac function and borderline personality disorder symptoms in adolescent non-suicidal self-injury. World J Biol Psychiatr. 2018;19:152-7.

56. Fischer G, Ameis N, Parzer P, Plener PL, Groschwitz R, Vonderlin E, Kölch M Brunner R, Kaess M. The German version of the self-injurious thoughts and behaviors interview (SITBI-G): a tool to assess non-suicidal self-injury and suicidal behavior disorder. BMC Psychiatr. 2014;14:265.

57. Gutierrez PM, Osman A. Adolescent suicide: an integrated approach to the assessment of risk and protective factors: Northern Illinois University Press; 2008.

58. Gutierrez PM, Osman A, Barrios FX, Kopper BA. Development and initial validation of the self-harm behavior questionnaire.J Pers Assess. 2001;77:475-90

59. Yen S, Kuehn K, Melvin C, Weinstock LM, Andover MS, Selby EA, Solomon $\mathrm{JB}$, Spirito A. Predicting persistence of nonsuicidal self-injury in suicidal adolescents. Suicide Life Threat Behav. 2016;46:13-22.

60. Lloyd-Richardson EE, Perrine N, Dierker L, Kelley ML. Characteristics and functions of non-suicidal self-injury in a community sample of adolescents. Psychol Med. 2007;37:1183-92.

61. Zanarini MC, Horwood J, Wolke D, Waylen A, Fitzmaurice G, Grant BF. Prevalence of DSM-IV borderline personality disorder in two community samples: 6,330 English 11-year-olds and 34,653 American adults. J Personal Disord. 2011;25:607-19.

62. Wilkinson P, Goodyer I. Non-suicidal self-injury. European Child Adolesc Psychiatr. 2011;20(2):103-8

63. Andrewes HE, Hulbert C, Cotton SM, Betts J, Chanen AM. Patterns of nonsuicidal self-injury and their relationship with suicide attempts in youth with borderline personality disorder. Archives Suicide Res. 2018;22:465-78.

64. Conway CC, Hipwell AE, Stepp SD. Seven-year course of borderline personality disorder features: borderline pathology is as unstable as depression during adolescence. Clin Psychol Sci. 2017;5:742-9.

65. Beauchaine TP, Gatzke-Kopp L, Mead HK. Polyvagal theory and developmental psychopathology: emotion dysregulation and conduct problems from preschool to adolescence. Biol Psychol. 2007:74:174-84.

66. Compas BE, Orosan PG, Grant KE. Adolescent stress and coping: implications for psychopathology during adolescence. J Adolesc. 1993:16:331.

67. Paus T. Mapping brain maturation and cognitive development during adolescence. Trends Cogn Sci. 2005;9:60-8.

Ready to submit your research? Choose BMC and benefit from:

- fast, convenient online submission

- thorough peer review by experienced researchers in your field

- rapid publication on acceptance

- support for research data, including large and complex data types

- gold Open Access which fosters wider collaboration and increased citations

- maximum visibility for your research: over $100 \mathrm{M}$ website views per year

At BMC, research is always in progress.

Learn more biomedcentral.com/submissions 